\title{
Adsorption of Basic Brown and Chrysophenine from Water Solution by Magnesium Silicate Gel
}

\author{
Zhun Zhao, ${ }^{1}$ Zhenhua Li, $^{2}$ Penglei Cui, ${ }^{3}$ Shengli Li, ${ }^{2}$ and Lingqian Kong ${ }^{2}$ \\ ${ }^{1}$ Chinese American Chemical Society, Houston, TX 77054, USA \\ ${ }^{2}$ Dongchang College, Liaocheng University, Shandong 252059, China \\ ${ }^{3}$ College of Science, Agricultural University of Hebei, Baoding 071001, China
}

Correspondence should be addressed to Lingqian Kong; lingqiankong@126.com

Received 25 March 2015; Revised 7 June 2015; Accepted 8 June 2015

Academic Editor: José Morillo Aguado

Copyright (C) 2015 Zhun Zhao et al. This is an open access article distributed under the Creative Commons Attribution License, which permits unrestricted use, distribution, and reproduction in any medium, provided the original work is properly cited.

\begin{abstract}
Noncrystalline, high surface area magnesium silicate gel was successfully prepared by hydrothermal method. Such product was characterized by BET and XRD to determine surface area $576.4 \mathrm{~m}^{2} \cdot \mathrm{g}^{-1}$, average pore width $2.76 \mathrm{~nm}$, and amorphous surface. The adsorption behaviors of Basic Brown and Chrysophenine on magnesium silicate gel were investigated through changing initial concentration, adsorbent dosage, solution $\mathrm{pH}$, contact time, and temperature. The experimental data was analyzed by the adsorption isotherms and kinetics. The results showed the adsorption progress was fast for Basic Brown, and the adsorption equilibrium was finished in $2 \mathrm{~h}$, while the adsorption equilibrium of Chrysophenine was finished in $7 \mathrm{~h}$. Freundlich isotherm model and secondorder kinetic models described the adsorption process very well.
\end{abstract}

\section{Introduction}

At present, dyes have been widely used in many fields, such as printing and dyeing, papermaking, textile, and food $[1,2]$. While the extensive usage makes such dyes attract considerable attention, the reason is that they may be toxic and nondegradable due to their syntheses from polyaromatic ring organics. Therefore, much effort has been dedicated to the pollution problem of dyes. So far, numerous treatment methods have been reported in removal of dyes from aqueous solution [3-6]. Among them, adsorption technique is recognized as a great potential based on the adsorbents presenting environmental friendliness, without second-pollution, high capacity, ease of use, and so on. One kind of the most used adsorbent is activated carbon [7]. However, to some extent, the natural properties of activated carbon, including high cost and nondegradability, greatly confine its usage in industry. Thus, it is of great importance to decrease the cost of wastewater treatment and explore new, inexpensive, highefficient adsorbents.

A survey revealed that many materials including chitosan, bagasse pith, peat, rice husk, fly ash, wood, and some natural minerals, such as bentonite, montmorillonite, alunite, sepiolite, zeolite, and diatomite, have been used as adsorbents to remove the dyes from solution [8-11]. A wide range of silicate materials had silanol group and magnesium hydroxide activated group accumulated on the surface. Some synthesized magnesium silicates displayed the common feature compared with that of natural materials and have been applied widely in removal of dyes, organics, and metal ions from the industry wastewater [12-23]. Our group also prepared some magnesium silicate materials with the similar surface activated groups and successfully removed the methylene blue and malachite green from water solution [17]. The other relative studies also have been reported [18-21, 2426].

Herein, we synthesized a kind of new, high special surface area and multiporous magnesium silicate gel through hydrothermal method. The adsorption experiments were performed by investigating the removal behavior of Basic Brown and Chrysophenine on the as-prepared magnesium silicate gel from water solution. This study provides the theory evidence and practice support for industrial wastewater treatment. 
<smiles>Nc1ccc(/N=N/c2cccc(/N=N/c3ccc(N)cc3N)c2)c(N)c1</smiles>

(a)<smiles>CCOc1ccc(N=Nc2ccc(C=Cc3ccc(N=Nc4ccc(OCC)cc4)cc3S(=O)(=O)O[Al])c(S(=O)(=O)O[NH])c2)cc1</smiles>

(b)

Figure 1: Molecular structure of Basic Brown (a) and Chrysophenine (b).

\section{Experimental}

2.1. Materials and Instruments. All chemical reagents were of analytical grade purity and used as received without further purification. All dyes were dried at $110^{\circ} \mathrm{C}$ for $2 \mathrm{~h}$ before using. All solutions were prepared with distilled water.

Basic Brown, industrial grade, is a dark brown-red powder with Color Index number 1 (21000) and CAS 8052-764. Its structure is shown in Figure 1(a), and the structural formula is $\mathrm{C}_{18} \mathrm{H}_{18} \mathrm{~N}_{8} \cdot 2 \mathrm{HCl}$. Chrysophenine, industrial grade, is a dark yellow powder with Color Index number 12 (24895) and CAS 2465-27-2. Its structure is shown in Figure 1(b), and its structural formula is $\mathrm{C}_{30} \mathrm{H}_{26} \mathrm{~N}_{4} \mathrm{Na}_{2} \mathrm{O}_{8} \mathrm{~S}_{2}$. The structures of the two dyes are given in Figure 1.

The surface area and pore-size distribution of magnesium silicate gel were determined by $\mathrm{N}_{2}$ adsorption/desorption analysis using ASAP 2020, Micromeritics. The surface area was evaluated by Brunauer-Emmett-Teller (BET) equation, and the pore-size distribution was determined by BarrettJoyner-Halenda (BJH) equation. The finial equilibrium concentration was measured by $722 \mathrm{UV}$-Vis spectrophotometer. Solution $\mathrm{pH}$ was determined through $\mathrm{pHS}-3 \mathrm{C}$ meter equipped with a combined $\mathrm{pH}$ electrode.

2.2. Synthesis of Magnesium Silicate Gel. Magnesium chloride hexahydrate and sodium silicate nonahydrate $\left(\mathrm{Na}_{2} \mathrm{O} / \mathrm{SiO}_{2}\right.$ module $=1$ ) were mixed with the mole ratio of $2: 1$ at room temperature. The resultant white precipitate appeared immediately. Keeping the precipitate stirring for $5 \mathrm{~h}$ at room temperature, then the turbid liquid was transited into reaction kettle for $24 \mathrm{~h}$ reaction at $120^{\circ} \mathrm{C}$. Finally, the reaction was cooled to room temperature, and the resultant samples were washed using heat water until without $\mathrm{Cl}^{-}$. The prepared adsorbent was dried in an air oven at $110^{\circ} \mathrm{C}$ for $10 \mathrm{~h}$ and allowed to cool naturally.

2.3. Adsorption Test. Adsorption experiments of Basic Brown and Chrysophenine on magnesium silicate gel were carried out through changing dyes initial concentration, adsorbent dosage, solution $\mathrm{pH}$, contact time, and temperatures.
Solution $\mathrm{pH}$ was adjusted by adding $0.1 \mathrm{~mol} \cdot \mathrm{L}^{-1} \mathrm{NaOH}$ or $\mathrm{HCl}$ solution and determined by using a pHS-3C meter equipped with a combined $\mathrm{pH}$ electrode. The $\mathrm{pH}$-meter was standardized with normal buffer solution (NBS) before measurement. After adsorption equilibrium was established, the residual concentration was measured by using a $722 \mathrm{UV}$ Vis spectrophotometer at the corresponding maximum wavelength. The percent of removal and adsorption capacity of the two dyes on magnesium silicate gel were calculated as the following equations:

$$
\begin{gathered}
E \%=\frac{C_{0}-C_{e}}{C_{0}} \times 100, \\
q_{e}=\frac{C_{0}-C_{e}}{m} \times V,
\end{gathered}
$$

where $E \%$ is the percent of removal after adsorption equilibrium; $C_{0}$ and $C_{e}$ are dyes initial concentration and equilibrium concentration, $\mathrm{mg} \cdot \mathrm{L}^{-1} ; q_{e}$ is the equilibrium adsorption capacity, mg. $\mathrm{g}^{-1} ; V$ is the volume of the solution, $\mathrm{L} ; m$ is the mass of adsorbent, $g$.

\section{Results and Discussion}

\subsection{Characterization of Adsorbent}

3.1.1. Analysis of Surface Area and Pore-Size Distribution. $\mathrm{N}_{2}$ adsorption/desorption isotherms and pore-size distribution are shown in Figure 2. The isotherms can be recognized as the classical IV type with a hysteresis loop in the relative pressure range of $0.85-1.0$, which indicates that the prepared magnesium gel possesses mesoporous structure. The $\mathrm{N}_{2}$ adsorption quantity fast increases under the low relative pressure and gradually increases as the relative pressure reaches 0.8 and then sharply increases when the relative pressure is between 0.8 and 1 . The maximum adsorption reaches $330 \mathrm{~cm}^{3} \cdot \mathrm{g}^{-1}$ when the relative pressure approaches 1 . The special surface area calculated from BET is $576.4 \mathrm{~m}^{2} \cdot \mathrm{g}^{-1}$, and the average pore width is $2.76 \mathrm{~nm}$. The pore-size distribution obtained from the desorption isotherm displayed a narrow distribution centering the range of $2 \mathrm{~nm}-4 \mathrm{~nm}$. 


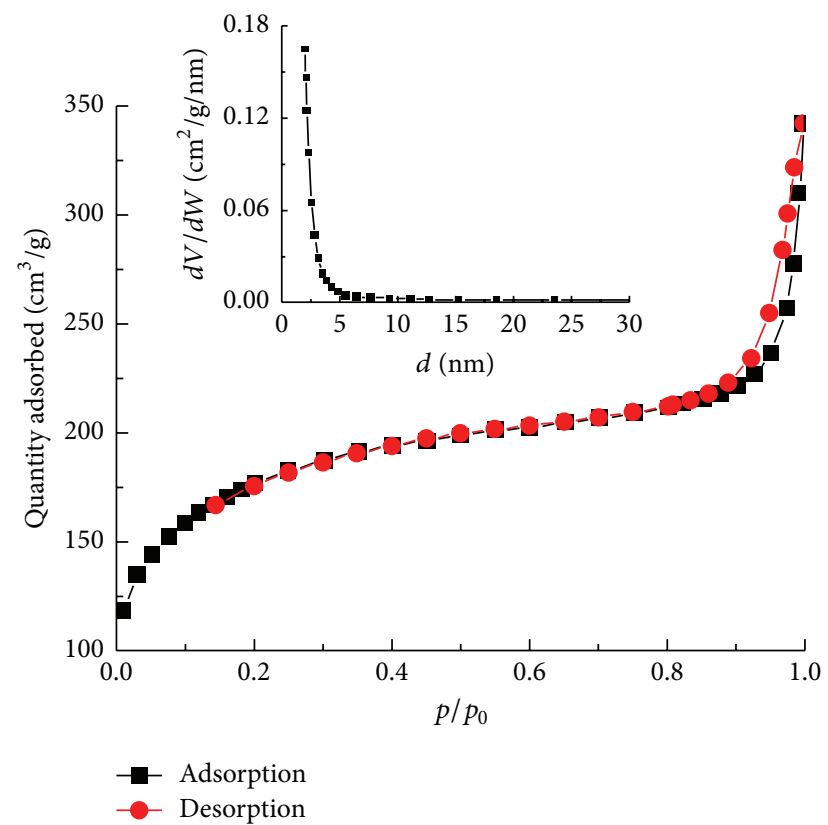

FIGURE 2: $\mathrm{N}_{2}$ adsorption/desorption isotherms and pore-size distribution (inset).

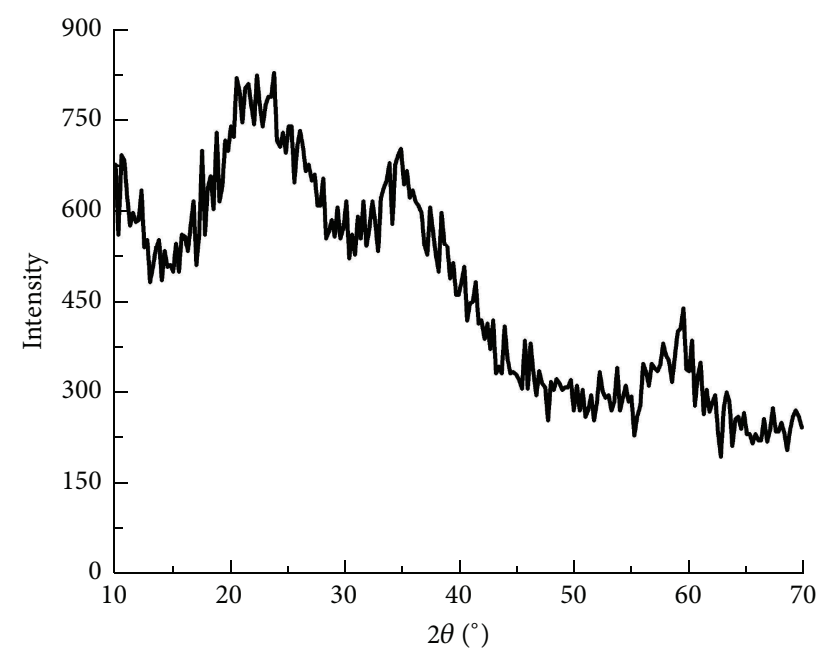

FIgURE 3: The X-ray powder diffraction (XRD) of magnesium silicate gel.

3.1.2. X-Ray Powder Diffraction (XRD) Analysis. The X-ray powder diffraction (XRD) of magnesium silicate gel is shown in Figure 3. The figure shows that the prepared sample is amorphous. The diffraction curve possesses three classical diffraction peaks, such as $20-30,32-38$, and $56-61^{\circ}$, which was consistent with the literature result $[18,19]$.

3.2. Effect of Initial Concentration. The effect of initial concentration of the two dyes on magnesium silicate gel can be investigated when the mass of adsorbent used was $2 \mathrm{~g} \cdot \mathrm{L}^{-1}$. The removal ratio of the two dyes on magnesium silicate gel as a function of dyes initial concentration was given in Figure 4 at $298 \mathrm{~K}$. As can be seen from the plot, the removal

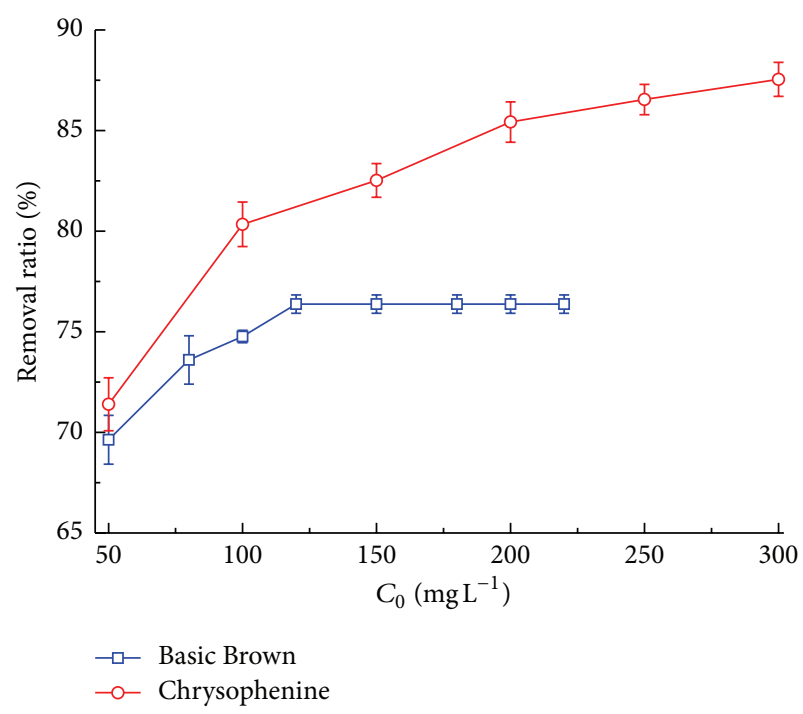

FIGURE 4: The adsorption effect of the two dyes on magnesium silicate gel as a function of initial concentration (mass of magnesium silicate gel: $2 \mathrm{~g} \cdot \mathrm{L}^{-1}$; adsorption time: $2 \mathrm{~h}$ for Basic Brown and $7 \mathrm{~h}$ for Chrysophenine; $\mathrm{pH}$ : 7.1).

ratio gradually increases with the increase of initial concentration; then the adsorption reached equilibrium. When the initial concentration of Basic Brown was $120 \mathrm{mg} \cdot \mathrm{L}^{-1}$, the removal ratio was $75 \%$. When the initial concentration of Chrysophenine was $200 \mathrm{mg} \cdot \mathrm{L}^{-1}$, the removal ratio was $85 \%$. Thus, the adsorption results of the two dyes illustrated that the adsorption processes were favorable. The performance also showed that the initial concentration provided an important driving force to overcome the mass transfer resistance of dye between the solution and adsorbents surface.

3.3. Effect of Mass of Adsorbent. The mass of magnesium silicate gel was in the range of $0.5-5 \mathrm{mg} \cdot \mathrm{L}^{-1}$, and the concentration of dyes was $200 \mathrm{mg} \cdot \mathrm{L}^{-1}$. The removal ratio of the two dyes on magnesium silicate gel was shown in Figure 4. As shown in Figure 5, the removal ratio of the two dyes gradually increases with the increase of mass of magnesium silicate gel. When the mass of magnesium silicate gel was lower than $2 \mathrm{~g} \cdot \mathrm{L}^{-1}$, the removal ratio of Chrysophenine sharply increases, and the removal coefficient of Basic Brown performed better than that of Chrysophenine. When the mass of magnesium silicate gel was higher, the removal of Chrysophenine displayed better adsorption coefficient than that of Basic Brown. When the mass was $5 \mathrm{~g} \cdot \mathrm{L}^{-1}$, the removal ratio of Chrysophenine was $90 \%$, and that of Basic Brown was $80 \%$.

3.4. Effect of Solution $p H$. The removal effect of Basic Brown and Chrysophenine on magnesium silicate gel as a function of solution $\mathrm{pH}$ was shown in Figure 6. As can be seen from the figure, there is no obvious effect on the removal of Chrysophenine, and the removal ratio keeps constant at $85 \%$. However, the solution $\mathrm{pH}$ has a significant effect on the removal of Basic Brown. At low $\mathrm{pH}(\mathrm{pH}<5)$, the adsorption 


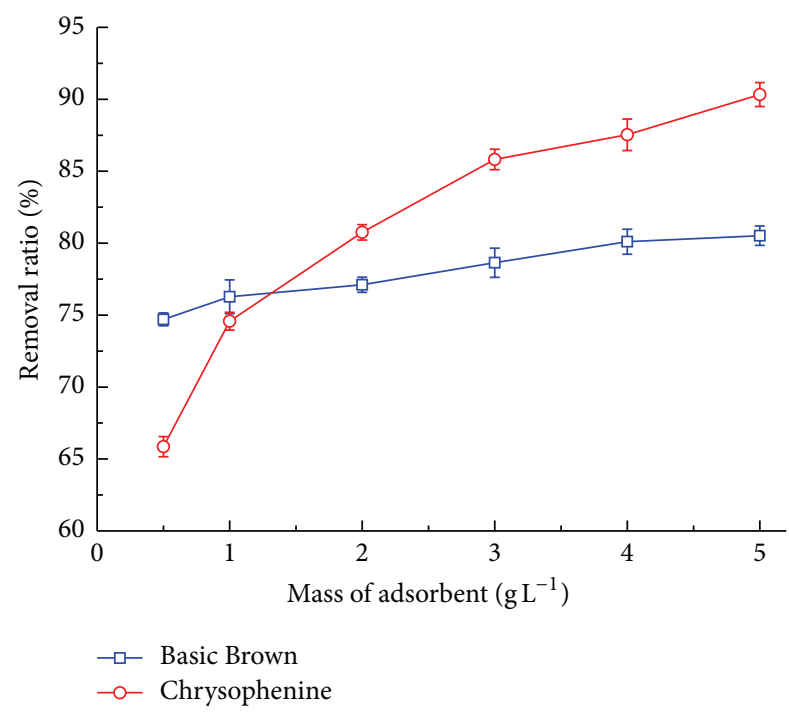

Figure 5: The effect of mass of magnesium silicate gel on the removal of Basic Brown and Chrysophenine (concentration of dyes: $200 \mathrm{mg} \cdot \mathrm{L}^{-1}$; adsorption time: $2 \mathrm{~h}$ for Basic Brown and $7 \mathrm{~h}$ for Chrysophenine; $\mathrm{pH}$ : 7.1).

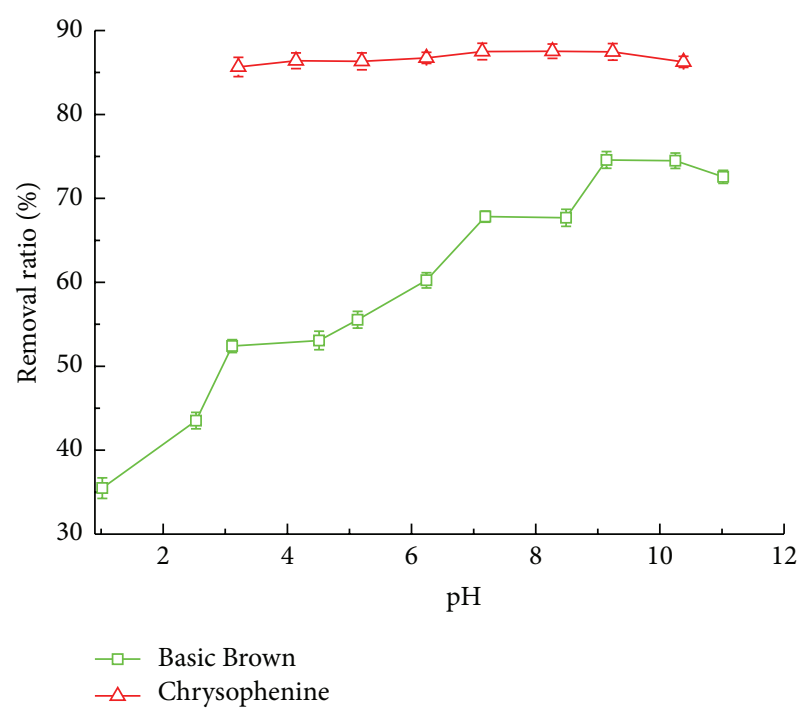

FIGURE 6: The effect of solution $\mathrm{pH}$ on the removal of the two dyes on magnesium silicate gel (concentration of dyes: $100 \mathrm{mg} \cdot \mathrm{L}^{-1}$; mass of adsorbent: $2 \mathrm{~g} \cdot \mathrm{L}^{-1}$; adsorption time: $2 \mathrm{~h}$ for Basic Brown and $7 \mathrm{~h}$ for Chrysophenine; $\mathrm{pH}: 7.1$ ).

efficiency was low. As the $\mathrm{pH}$ increased, the removal ratio gradually increased and reached the maximum value of $75 \%$. When $\mathrm{pH}$ continued to increase, the removal ratio began to decrease. Therefore, the best adsorption efficiency was obtained with the solution $\mathrm{pH}$ of 9 .

3.5. Effect of Contact Time. At $298 \mathrm{~K}$, the adsorption effect of Basic Brown and Chrysophenine on magnesium silicate gel as a function of different contact time was shown in Figure 7. As can be seen, the adsorption of Basic Brown was

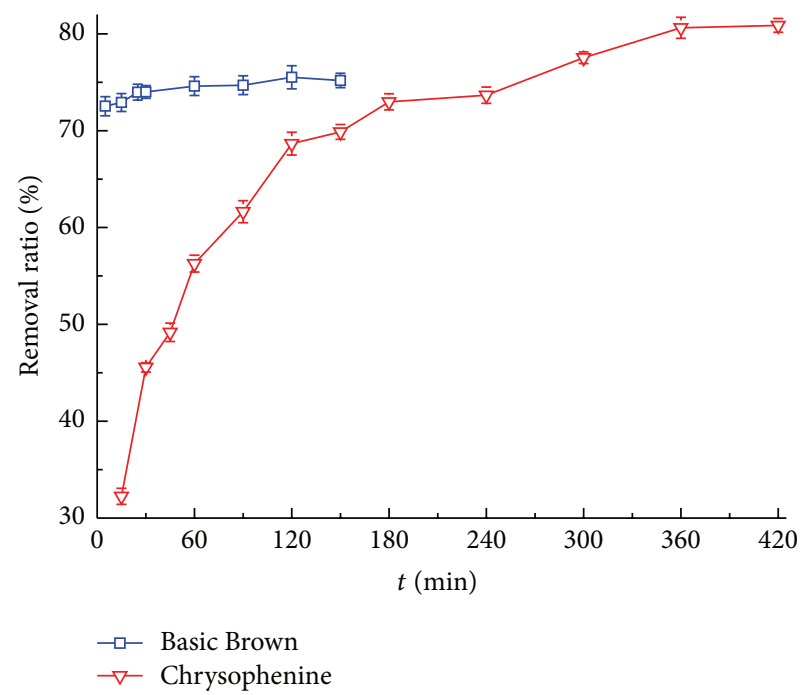

Figure 7: The effect of contact time on the removal of the two dyes on magnesium silicate gel (concentration of dyes: $100 \mathrm{mg} \cdot \mathrm{L}^{-1}$; mass of adsorbent: $\left.2 \mathrm{~g} \cdot \mathrm{L}^{-1} ; \mathrm{pH}: 7.1\right)$.

a fast adsorption process, and the adsorption equilibrium was finished in a relative short time with the removal ration of $73 \%$. The adsorption of Chrysophenine on magnesium silicate gel exhibited three different stages: the fast adsorption process, the slow adsorption course, and the final adsorption equilibrium.

3.6. Adsorption Isotherms. The effect of adsorption temperature on the removal of Basic Brown and Chrysophenine is shown in Figure 8. As shown in the figure, there is no obvious change for the removal of the two dyes on magnesium silicate gel at the different temperatures. The equilibrium adsorption quantity gradually increased with the increase of the concentration. The adsorption quantity of Basic Brown was $76.6 \mathrm{mg} \cdot \mathrm{g}^{-1}$, when the initial concentration was $200 \mathrm{mg} \cdot \mathrm{L}^{-1}$, while the adsorption quantity of Chrysophenine was $57.8 \mathrm{mg} \cdot \mathrm{g}^{-1}$ with the same initial concentration.

The Langmuir and Freundlich adsorption models have been used to fit the experimental data at different adsorption temperatures:

$$
\begin{gathered}
\text { Langmuir: } \frac{C_{e}}{q_{e}}=\frac{1}{q_{m} K_{L}}+\frac{C_{e}}{q_{m}}, \\
\text { Freundlich: } \lg q_{e}=\lg K_{F}+\frac{1}{n} \lg C_{e},
\end{gathered}
$$

where $C_{e}$ is equilibrium concentration, $\mathrm{mg} \cdot \mathrm{L}^{-1} ; q_{e}$ is the equilibrium adsorption capacity, $\mathrm{mg} \cdot \mathrm{g}^{-1} ; q_{m}$ is the maximum adsorption quantity, mg.g ${ }^{-1} ; K_{L}, K_{F}$, and $n$ are adsorption constants.

The analysis revealed that the adsorption isotherms did not meet the Langmuir adsorption model, which indicated the adsorption of Basic Brown and Chrysophenine on magnesium silicate gel was not simple single-molecule adsorption. The Freundlich adsorption model can describe the 


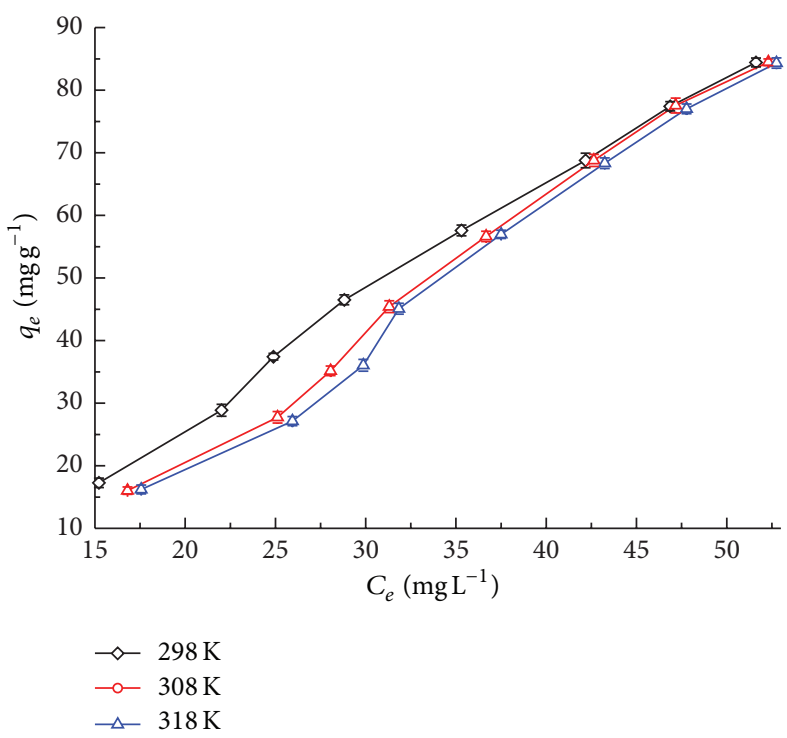

(a)

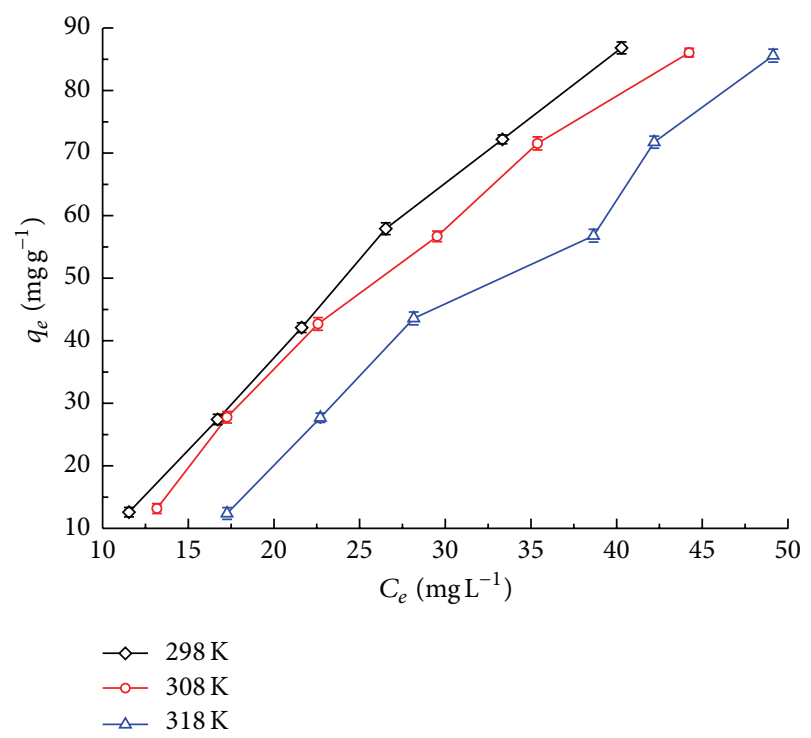

(b)

Figure 8: Adsorption isotherms of Basic Brown (a) and Chrysophenine (b) at different adsorption temperatures.

TABLE 1: The relative parameters of Freundlich adsorption isotherm model.

\begin{tabular}{lccccc}
\hline \multirow{2}{*}{ Dyes } & $C_{0}$ & \multirow{2}{*}{$\mathrm{T} / \mathrm{K}$} & \multicolumn{3}{c}{ Freundlich model } \\
& $\mathrm{mg} \cdot \mathrm{L}^{-1}$ & & $K_{F}$ & $1 / n$ & $R^{2}$ \\
\hline \multirow{3}{*}{ Basic Brown } & 200 & 298 & 0.5629 & 1.2849 & 0.9888 \\
& 200 & 308 & 0.2473 & 1.49 & 0.9895 \\
& 200 & 318 & 0.1802 & 1.565 & 0.9876 \\
\hline \multirow{3}{*}{ Chrysophenine } & 200 & 298 & 0.3574 & 1.5201 & 0.9742 \\
& 200 & 308 & 0.2998 & 1.5327 & 0.9450 \\
& 200 & 318 & 0.0738 & 1.8268 & 0.9556 \\
\hline
\end{tabular}

adsorption process of the two dyes very well, and the square correlation coefficient value of Basic Brown approached 0.97, while the coefficient value of Chrysophenine was 0.94 . The corresponding parameters are given in Table 1.

3.7. Adsorption Kinetics. At different adsorption temperatures, the removal of Basic Brown and Chrysophenine on magnesium silicate gel at different adsorption time was shown in Figure 9. As can be seen from the figure, the adsorption quantity gradually increased with the extension of contact time, while, at the same contact time, the adsorption quantity slowly decreased with the temperature increasing.

In order to investigate the adsorption kinetics behavior, the first-order kinetic and second-order kinetic models were used to discuss the adsorption mechanism.

The first-order kinetics equation is presented as

$$
\ln \left(q_{e}-q_{t}\right)=\ln q_{e}-k_{1} t
$$

where $q_{e}$ is the amount adsorbed at equilibrium, mg/g; $q_{t}$ is the amount adsorbed at time $t, \min ; k_{1}$ is the first-order rate constant of adsorption, $\mathrm{min}^{-1}$, which can be determined from the slopes of the plots $\ln \left(q_{e}-q_{t}\right)$ versus $t$.
The second-order kinetics equation is given as

$$
\frac{t}{q_{t}}=\frac{1}{k_{2} q_{e}{ }^{2}}+\frac{t}{q_{e}},
$$

where $k_{2}$ is the second-order rate constant of adsorption, $\mathrm{g} / \mathrm{mg} / \mathrm{min}$, which can be obtained from the slopes and intercepts of plots $t / q_{t}$ versus $t$.

The experimental data was analyzed through the firstorder kinetics model and second-order kinetics model, respectively. The corresponding kinetics parameters were obtained from (3)-(4) and given in Table 2. It can be seen that the calculated equilibrium adsorption quantity and experimental adsorption quantity were close and that the correlation coefficient values approached $1\left(R_{2}>0.99\right)$. Therefore, the obtained parameters showed that the secondorder kinetics model could describe the adsorption process very well.

\section{Conclusions}

A kind of high special surface area adsorbent, magnesium silicate gel, was prepared through hydrothermal synthesis. The calculated special surface area was $576.4 \mathrm{~m}^{2} \cdot \mathrm{g}^{-1}$, and the average pore width was $2.76 \mathrm{~nm}$. The adsorption experiments showed that the removal ratio gradually increased with the increase of initial concentration, mass of adsorbent, solution $\mathrm{pH}$, and contact time as well as the decrease of the temperature. The adsorption quantity of Basic Brown was $76.5 \mathrm{mg} \cdot \mathrm{g}^{-1}$ and the adsorption quantity of Chrysophenine was $57.8 \mathrm{mg} \cdot \mathrm{g}^{-1}$ with the initial concentration of $200 \mathrm{mg} \cdot \mathrm{L}^{-1}$ for both dyes, respectively. The adsorption equilibriums were finished in a short time for removal of Basic Brown, and the adsorption process of the two dyes performed physical 
TABLE 2: Second-order kinetics values calculated for the adsorption of the two dyes on magnesium silicate gel.

\begin{tabular}{|c|c|c|c|c|c|c|c|c|}
\hline \multirow{2}{*}{ Dyes } & \multirow{2}{*}{$\begin{array}{c}C_{0} \\
\mathrm{mg} \cdot \mathrm{g}^{-1}\end{array}$} & \multirow{2}{*}{$T / \mathrm{K}$} & \multicolumn{2}{|c|}{ First-order } & \multicolumn{4}{|c|}{ Second-order } \\
\hline & & & $k_{1} / \min ^{-1}$ & $R^{2}$ & $q_{e, \exp } / \mathrm{mg} \cdot \mathrm{g}^{-1}$ & $q_{e, \mathrm{cal}} / \mathrm{mg} \cdot \mathrm{g}^{-1}$ & $k_{2} / \mathrm{g} \cdot \mathrm{mg}^{-1} \cdot \min ^{-1}$ & $R^{2}$ \\
\hline \multirow{3}{*}{ Basic Brown } & & 298 & 0.0187 & 0.951 & 76.6 & 76.92 & 0.0180 & 1.000 \\
\hline & & 308 & 0.0377 & 0.973 & 76.4 & 76.92 & 0.0133 & 1.000 \\
\hline & & 318 & 0.0043 & 0.944 & 76.1 & 74.07 & 0.0190 & 1.000 \\
\hline \multirow{3}{*}{ Chrysophenine } & & 298 & 0.0092 & 0.972 & 56.8 & 60.61 & $5.44 \times 10^{-4}$ & 0.9975 \\
\hline & & 308 & 0.0079 & 0.994 & 76.4 & 58.82 & $5.47 \times 10^{-4}$ & 0.9980 \\
\hline & & 318 & 0.009 & 0.993 & 76.1 & 57.47 & $4.90 \times 10^{-4}$ & 0.9974 \\
\hline
\end{tabular}

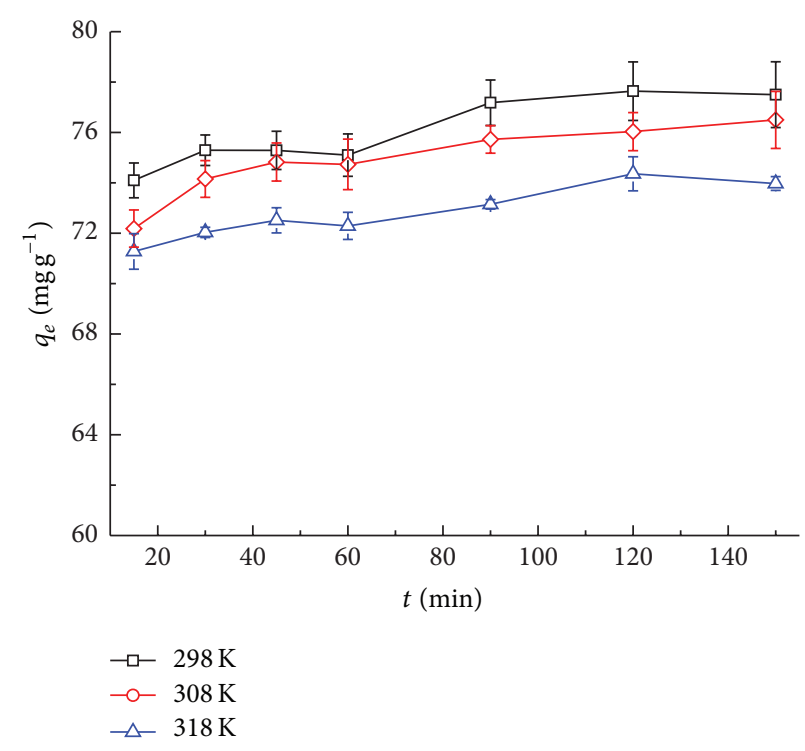

(a)

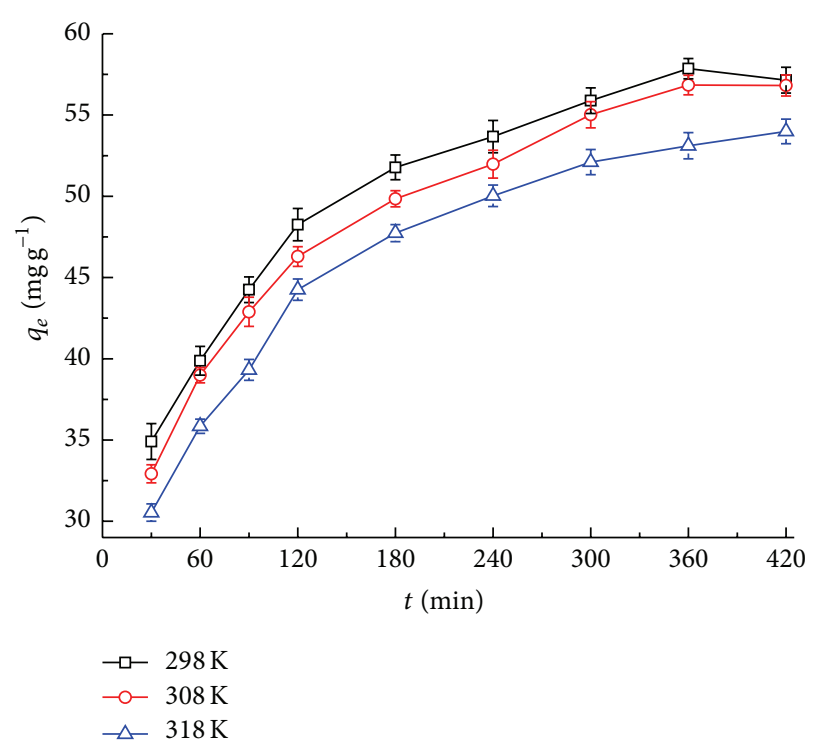

(b)

FIgURE 9: The adsorption kinetics of Basic Brown (a) and Chrysophenine (b) at different adsorption time.

adsorption. Freundlich adsorption isotherm and secondorder kinetics models well described the adsorption behavior of the two dyes on magnesium silicate gel.

\section{Conflict of Interests}

The authors declare that there is no conflict of interests regarding the publication of this paper.

\section{Authors' Contribution}

Zhenhua Li and Zhun Zhao contributed equally to this study.

\section{Acknowledgment}

The authors are grateful for financial support of this work from the Science and Technology Project in Colleges and Universities in Shandong Province (J10LB61).

\section{References}

[1] T. Robinson, B. Chandran, and P. Nigam, "Removal of dyes from a synthetic textile dye effluent by biosorption on apple pomace and wheat straw," Water Research, vol. 36, no. 11, pp. 2824-2830, 2002.

[2] P. Nigam, G. Armour, I. M. Banat, D. Singh, and R. Marchant, "Physical removal of textile dyes from effluents and solidstate fermentation of dye-adsorbed agricultural residues," Bioresource Technology, vol. 72, no. 3, pp. 219-226, 2000.

[3] P. Cañizares, F. Martínez, C. Jiménez, J. Lobato, and M. A. Rodrigo, "Coagulation and electrocoagulation of wastes polluted with dyes," Environmental Science and Technology, vol. 40, no. 20, pp. 6418-6424, 2006.

[4] J. Marto, P. S. Marcos, T. Trindade, and J. A. Labrincha, "Photocatalytic decolouration of orange II by $\mathrm{ZnO}$ active layers screenprinted on ceramic tiles," Journal of Hazardous Materials, vol. 163, no. 1, pp. 36-42, 2009.

[5] E. Razo-Flores, M. Luijten, B. A. Donlon, G. Lettinga, and J. A. Field, "Complete biodegradation of the azo dye azodisalicylate under anaerobic conditions," Environmental Science and Technology, vol. 31, no. 7, pp. 2098-2103, 1997.

[6] M. A. Al-Ghouti, J. Li, Y. Salamh, N. Al-Laqtah, G. Walker, and M. N. M. Ahmad, "Adsorption mechanisms of removing heavy metals and dyes from aqueous solution using date pits solid adsorbent," Journal of Hazardous Materials, vol. 176, no. 1-3, pp. 510-520, 2010.

[7] P. S. Kumar, S. Ramalingam, and K. Sathishkumar, "Removal of methylene blue dye from aqueous solution by activated carbon 
prepared from cashew nut shell as a new low-cost adsorbent," Korean Journal of Chemical Engineering, vol. 28, no. 1, pp. 149155, 2011.

[8] S. Zaheer, H. N. Bhatti, S. Sadaf, Y. Safa, and M. Zia-urRehman, "Biosorption characteristics of sugarcane bagasse for the removal of Foron Blue E-Bl dye from aqueous solutions," Journal of Animal and Plant Sciences, vol. 24, no. 1, pp. 272-279, 2014.

[9] S. Sadaf, H. N. Bhatti, S. Ali, and K.-U. Rehman, "Removal of Indosol Turquoise FBL dye from aqueous solution by bagasse, a low cost agricultural waste: batch and column study," Desalination and Water Treatment, vol. 52, no. 1-3, pp. 184-198, 2014.

[10] S. Noreen and H. N. Bhatti, "Fitting of equilibrium and kinetic data for the removal of Novacron Orange P-2R by sugarcane bagasse," Journal of Industrial and Engineering Chemistry, vol. 20, no. 4, pp. 1684-1692, 2014.

[11] S. Sadaf, H. N. Bhatti, S. Nausheen, and M. Amin, "Application of a novel lignocellulosic biomaterial for the removal of Direct Yellow 50 dye from aqueous solution: batch and column study," Journal of the Taiwan Institute of Chemical Engineers, vol. 47, pp. 160-170, 2015.

[12] A. M. Sevim, R. Hojiyev, A. Gül, and M. S. Çelik, "An investigation of the kinetics and thermodynamics of the adsorption of a cationic cobalt porphyrazine onto sepiolite," Dyes and Pigments, vol. 88, no. 1, pp. 25-38, 2011.

[13] C. A. P. Almeida, N. A. Debacher, A. J. Downs, L. Cottet, and C. A. D. Mello, "Removal of methylene blue from colored effluents by adsorption on montmorillonite clay," Journal of Colloid and Interface Science, vol. 332, no. 1, pp. 46-53, 2009.

[14] M. Alkan, Ö. Demirbaş, and M. Doğan, "Adsorption kinetics and thermodynamics of an anionic dye onto sepiolite," Microporous and Mesoporous Materials, vol. 101, no. 3, pp. 388-396, 2007.

[15] M. C. Wilding, C. J. Benmore, and J. K. R. Weber, "In situ diffraction studies of magnesium silicate liquids," Journal of Materials Science, vol. 43, no. 14, pp. 4707-4713, 2008.

[16] Y. Zhu, D. Jian, and S. Wang, "Synthesis of mesoporous magnesium silicate particles and their adsorption property," Micro \& Nano Letters, vol. 6, no. 8, pp. 671-674, 2011.

[17] L. L. Zhang, H. Z. Wang, and H. Yang, "Synthesis and adsorption behavior of magnesium silicate gels," Journal of Salt and Chemical Industry, vol. 40, pp. 15-19, 2011.

[18] Y. Q. Wang, G. Z. Wang, H. Q. Wang, C. Liang, W. Cai, and L. Zhang, "Chemical-template synthesis of micro/nanoscale magnesium silicate hollow spheres for waste-water treatment," Chemistry, vol. 16, no. 11, pp. 3497-3503, 2010.

[19] A. S. Özcan, Ş. Tetik, and A. Özcan, "Adsorption of acid dyes from aqueous solutions onto sepiolite," Separation Science and Technology, vol. 39, no. 2, pp. 301-320, 2004.

[20] M. M. Abou-Mesalam and I. M. El-Naggar, "Selectivity modification by ion memory of magneso-silicate and magnesium alumino-silicate as inorganic sorbents," Journal of Hazardous Materials, vol. 154, no. 1-3, pp. 168-174, 2008.

[21] F. Ciesielczyk, A. Krysztafkiewicz, and T. Jesionowski, "Magnesium silicates-adsorbents of organic compounds," Applied Surface Science, vol. 253, no. 20, pp. 8435-8442, 2007.

[22] D. R. M. Brew and F. P. Glasser, "Synthesis and characterisation of magnesium silicate hydrate gels," Cement and Concrete Research, vol. 35, no. 1, pp. 85-98, 2005.

[23] I. M. Ali, Y. H. Kotp, and I. M. El-Naggar, "Thermal stability, structural modifications and ion exchange properties of magnesium silicate," Desalination, vol. 259, no. 1-3, pp. 228-234, 2010.
[24] Z. Zhao, Y.-L. Fang, P. J. J. Alvarez, and M. S. Wong, "Degrading perchloroethene at ambient conditions using Pd and Pd-onAu reduction catalysts," Applied Catalysis B: Environmental, vol. 140-141, pp. 468-477, 2013.

[25] Z. Zhao, J. Arentz, L. A. Pretzer et al., "Volcano-shape glycerol oxidation activity of palladium-decorated gold nanoparticles," Chemical Science, vol. 5, no. 10, pp. 3715-3728, 2014.

[26] Z. Zhao, J. T. Miller, T. Wu, N. M. Schweitzer, and M. S. Wong, "EXAFS characterization of palladium-on-gold catalysts before and after glycerol oxidation," Topics in Catalysis, vol. 58, no. 4, pp. 302-313, 2015. 

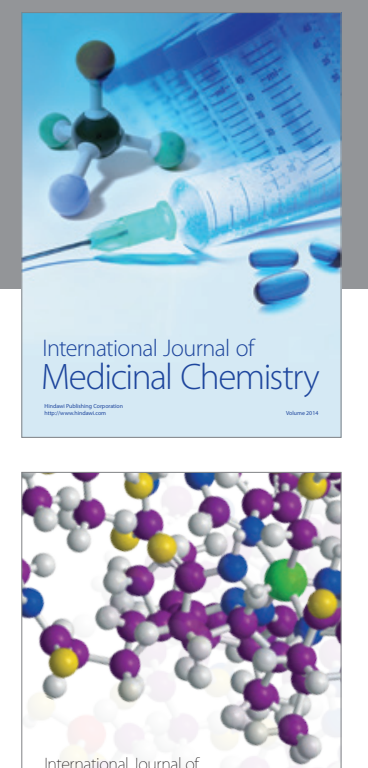

\section{Carbohydrate} Chemistry

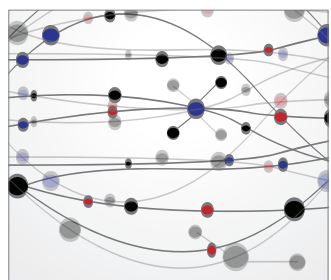

The Scientific World Journal
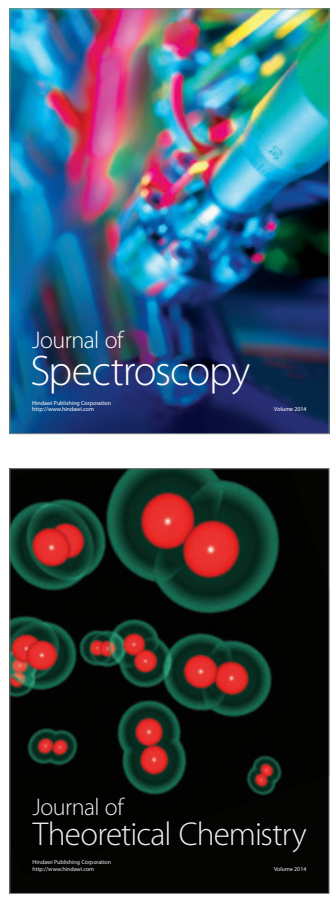
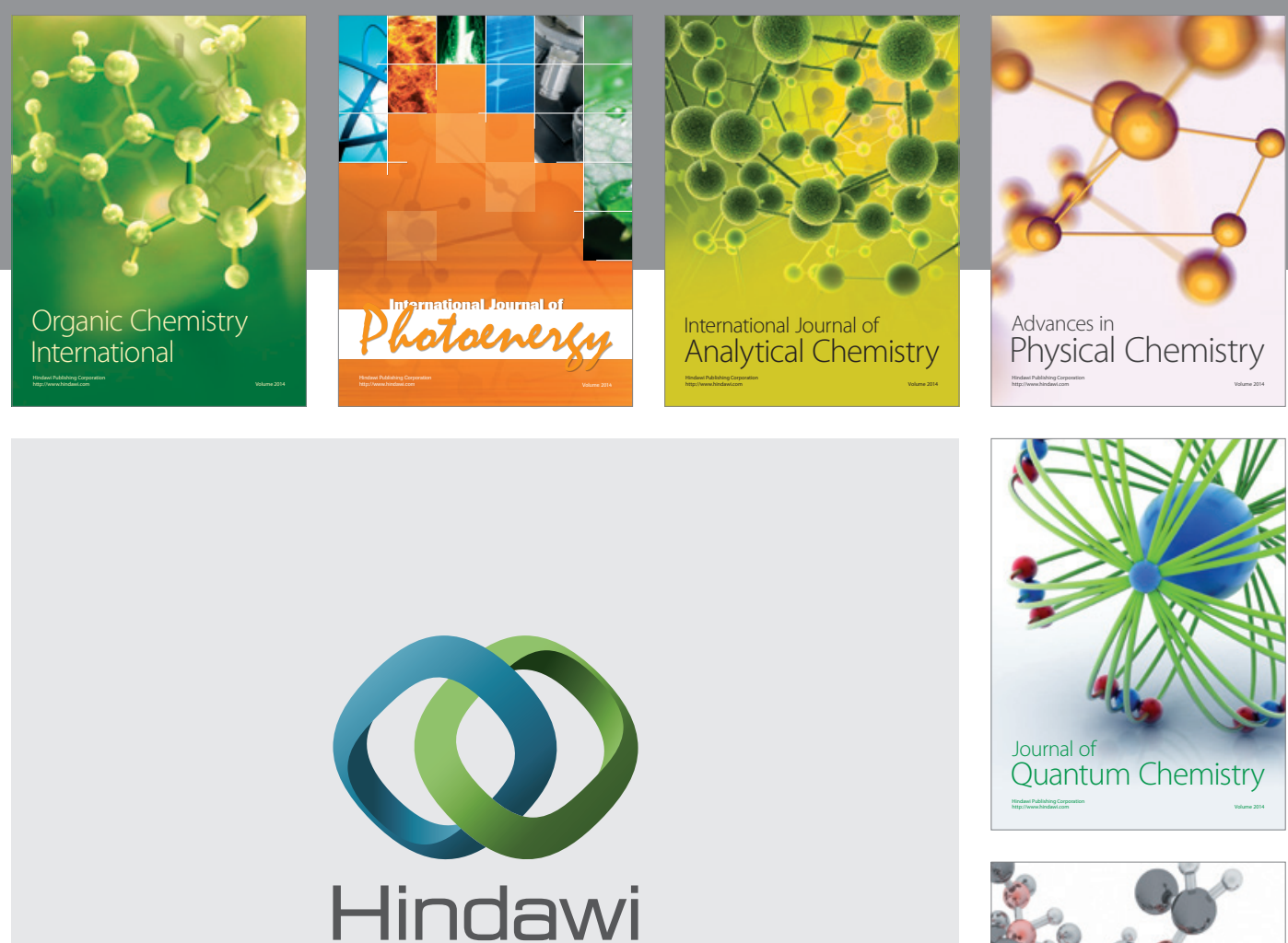

Submit your manuscripts at

http://www.hindawi.com

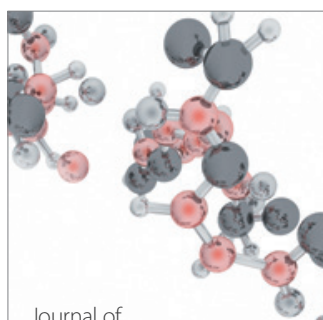

Analytical Methods

in Chemistry

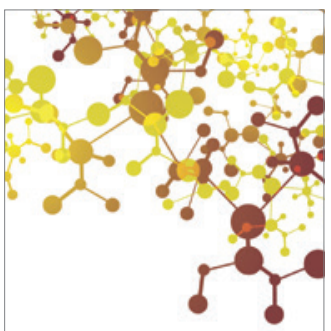

Journal of

Applied Chemistry

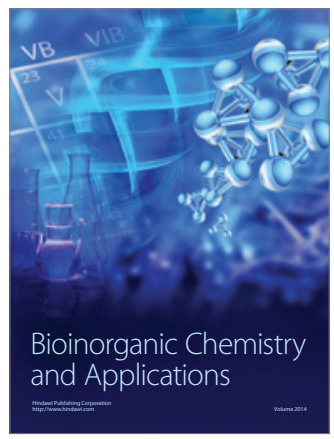

Inorganic Chemistry
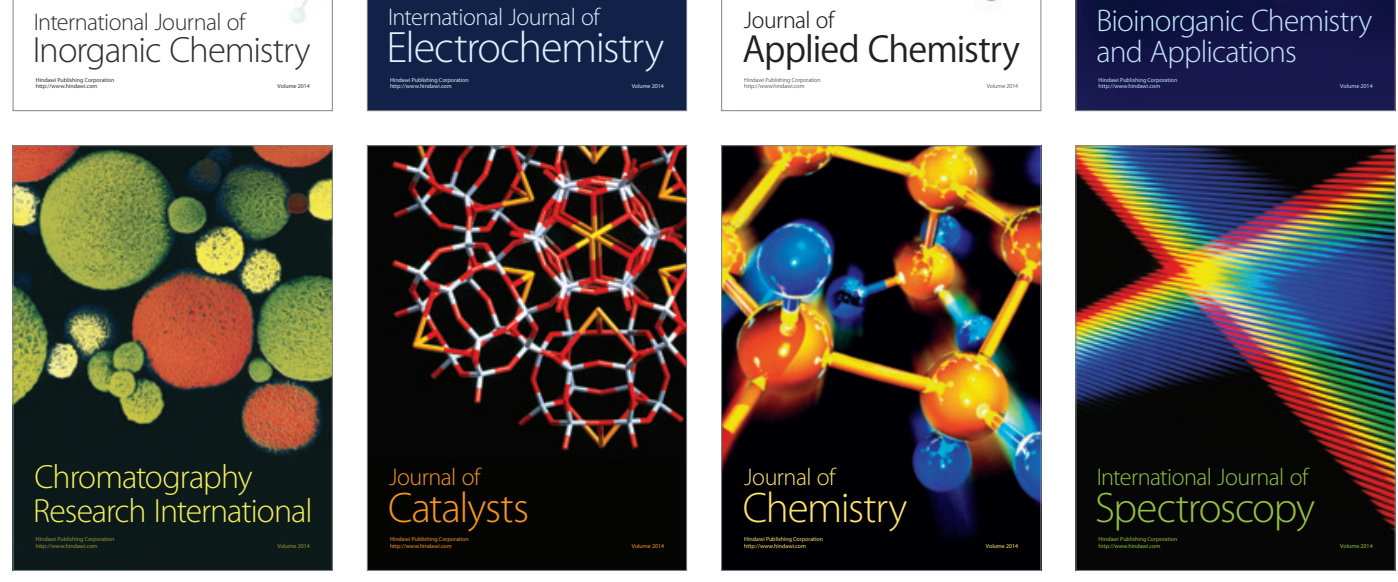